\title{
Smilacaceae endémicas del Perú
}

\section{Blanca León ${ }^{1,2}$}

${ }^{1}$ Museo de Historia Natural, Av. Arenales 1256, Aptdo. 14-0434, Lima 14, Perú

2 Plant Resources Center, University of Texas at Austin, Austin TX 78712 EE.UU.

blanca.leon@mail.utexas.edu

\section{Resumen}

La familia Smilacaceae es reconocida en el Perú por presentar un género, Smilax, y diecinueve especies (Brako \& Zarucchi, 1993; Ulloa Ulloa et al., 2004), principalmente lianas y bejucos. En este trabajo reconocemos cuatro especies endémicas. Se asignó la categoría de amenaza de la UICN a dos especies. Los taxones endémicos se encuentran en bosques de la región del Bosque Húmedo Amazónico, por debajo de los $100 \mathrm{~m}$ de altitud. No se encuentra representada dentro de áreas naturales protegidas.

Palabras claves: Smilacaceae, Perú, endemismo, plantas endémicas.

\section{Abstract}

The Smilacaceae are represented in Peru by one genus, Smilax, and nineteen species (Brako \& Zarucchi, 1993; Ulloa Ulloa et al., 2004), mainly lianas and vines. Here we recognize four endemic species. We assigned IUCN threat categories to two species. The endemic taxa occur in the Humid Amazonian Forest region, below 100 m elevation, and have not yet been registered inside a Peruvian protected area.

Keywords: Smilacaceae, Peru, endemism, endemic plants.

\section{Smilax colubrina J.F. Macbr.}

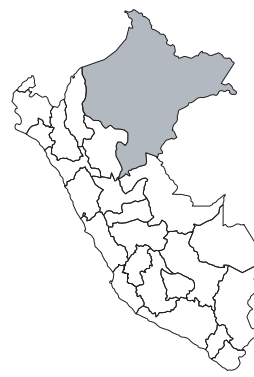

Publicación: Field Mus. Nat. Hist., Bot. Ser. 11(2): 45-46. 1931.

Colección tipo: G. Klug 1327

Herbarios: F, NY.

Nombre común: Desconocido.

Registro departamental: LO.

Regiones Ecológicas: BHA; $100 \mathrm{~m}$.

SINANPE: Sin registro.

Herbarios peruanos: Ninguno

Observaciones: Bejuco descrito de una planta recolectada en 1930, de los alrededores de Iquitos. Esta familia necesita una revisión taxonómica moderna. No ha sido posible evaluarla, ni asignarle una categoría.

\section{Smilax gilva J.F. Macbr.}

Publicación: Field Mus. Nat. Hist., Bot. Ser. 11(2): 44—45. 1931.

Colección tipo: G. Klug 874

Herbarios: F, NY.

Nombre común: Desconocido.

Registro departamental: LO.

Regiones Ecológicas: BHA; $100 \mathrm{~m}$.

SINANPE: Sin registro,

Herbarios peruanos: Ninguno.

Observaciones: Bejuco descrito de una planta recolectada en 1930 ,de los alrededores de Iquitos, como Smilax colubrina. Esta familia necesita una revisión taxonómica moderna. No ha sido posible evaluarla, ni asignarle una categoría.
3. Smilax vaga J.F. Macbr.

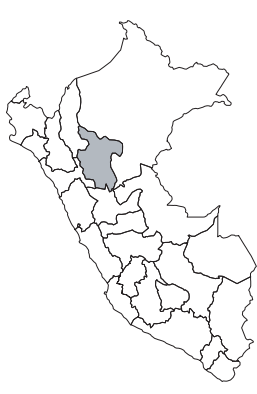

DD

Publicación: Field Mus. Nat. Hist., Bot. Ser. 11(2): 46. 1931.

Colección tipo: L. Williams 6757

Herbarios: F.

Nombre común: Desconocido.

Registro departamental: SM.

Regiones Ecológicas: BHA; altitud desconocida.

SINANPE: Sin registro.

Herbarios peruanos: Ninguno.

Observaciones: Bejuco conocido aparentemente sólo de la colección tipo, una planta recolectada en 1929 de los alrededores de Tarapoto, en la cuenca del Mayo.

\section{Smilax williamsi J.F. Macbr.}

\section{DD}

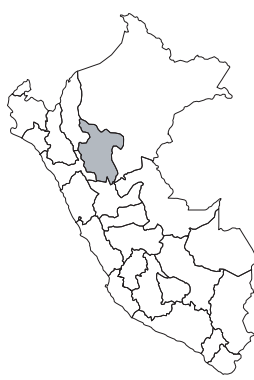

Publicación: Field Mus. Nat. Hist., Bot. Ser. 11(2): 46. 1931.

Colección tipo: L. Williams 5432

Herbarios: F.

Nombre común: Desconocido.

Registro departamental: SM.

Regiones Ecológicas: Sin datos; altitud desconocida.

SINANPE: Sin registro.

Herbarios peruanos: Ninguno.

Observaciones: Bejuco aparentemente conocido sólo de la colección tipo, una planta recolectada en 1929, de la cuenca del Mayo. Se desconoce el estado de sus poblaciones. 